In support of the FDA decision to clear aspartame for general consumption, excepting phenylketonuric children, a study of 126 apparently healthy children and adolescents showed that there were no clinically significant differences documented between the children taking aspartame and those taking sucrose for a 13 week period, regardless of age between 2 and 21 years. Aspartame appeared to be a safe sweetening agent for use by healthy children aged 2 or older. (Frey GH. J Toxicology Environmental Health 1976; 2:401.) However, studies of aspartame in children with neuropsychiatric problems are limited, and adequate data are not available to establish its safety and freedom from adverse effects. Until more specific investigations are completed to determine the effects of aspartame on seizure control it might be advisable to limit or avoid the ingestion of aspartame products in children with seizures and particularly poorly controlled absence seizures (Camfield et al. 1992). See Millichap JG. Nutrition, Diet and Child's Behavior. Charles C. Thomas, Springfield, 1986 for a review of the effects of aspartame on diseases of the nervous system in children.

\title{
ALCOHOL AND MENTAL DEVELOPMENT
}

In a prospective follow-up study at the University of Helsinki, Finland, 60 children exposed to alcohol in utero were assessed by a psychologist (Bayley Mental scale) and a speech therapist (Reynell Verbal Comprehension scale) at a mean age of 27 months. Forty-eight non-exposed children were also examined to set the -2 SD limit for subnormal performance. In children exposed to heavy drinking during the first trimester only, no definite effect on mental or language development was demonstrated. Children exposed throughout pregnancy scored significantly lower than those subjected to alcohol during the first trimester only. The diagnosis of fetal alcohol syndrome was made in 7 children, 1 exposed during the first and second trimesters, and 6 exposed throughout pregnancy. The lower limit for heavy drinking was more than 10 drinks a week, or more than 45 drinks per month. The drinking patterns of these mothers varied from 1 to 20 drinks per day. (Autti-Ramo I et al. Mental development of 2-year-old children exposed to alcohol in utero. J Pediatr May 1992; 120:740-746.) (Reprints: Dr. Ilona AuttiRamo, Peuramaentie 1 H 18, 02700 Kauniainen, Finland.)

COMMENT. Fetal alcohol exposure causes a continuum of developmental defects ranging from mental retardation to slight developmental difficulties. The identification of mothers who are heavy drinkers in early pregnancy and effective counseling should help to preserve the developmental potential of the fetus. 